\title{
Application of an inverse neural network model for the identification of optimal amendment to reduce Copper toxicity in phytoremediated contaminated soils
}

\author{
Nour HATTAB ${ }^{\mathrm{a}, \mathrm{b}, \mathrm{c}^{*}}$, Mikael MOTELICA-HEINO ${ }^{\mathrm{a}}$
}

${ }^{\mathrm{a}}$ ISTO

UMR 7327 - CNRS/Université d'Orléans

Campus Géosciences, 1A, Rue de la Férollerie, 45071 Orléans cedex 2, France.

Mail: nour.hattab@univ-orleans.fr

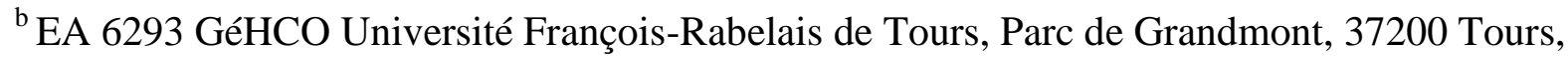
France

${ }^{c}$ Laboratory of Soil Science, Faculty of Agriculture, University of Damascus, Damascus, Syria.

\begin{abstract}
Artificial neural network ANN prediction approaches applied to the modeling of soil behavior are often solved in the forward direction, by measuring the response of the soil (outputs) to a given set of soil inputs. Conversely, one may be interested in the assessment of a given set of soil inputs that leads to given (target) soil outputs. This is the inverse of the former problem. In this study, we develop and test an inverse artificial neural network model for the prediction of the optimal soil treatment to reduce copper $(\mathrm{Cu})$ toxicity assessed by a given target concentration of $\mathrm{Cu}$ in dwarf bean leaves (BL) from selected soil inputs. In this study the inputs are the soil $\mathrm{pH}$, electrical conductivity (EC), dissolved organic carbon (DOC) and a given target toxicity value of $\mathrm{Cu}$, whereas the output is the best treatment to reduce the given toxicity level. It is shown that the proposed method can successfully identify the best soil treatment from the soil properties (inputs). Two important challenges for optimal treatment prediction using neural networks are the nonuniqueness of the solution of the inverse problem and the inaccuracies in the measurement of the soil properties (inputs). It is shown that the neural network prediction model proposed can overcome both these challenges. It is also shown that the proposed inverse neural network method
\end{abstract}


can potentially be applied with a high level of success to the phytoremediation of contaminated soils. Before large-scale application, further validation is needed by performing several experiments and investigations including additional factors and their combinations to capture the complex soil behavior.

Keywords: Soil contamination, Copper, Amendment optimization, Artificial neural networks (ANN), Inverse modeling

\section{Introduction}

Soils contaminated with trace elements have serious consequences for terrestrial ecosystems, agricultural production and human health (Adriano, 2001). Trace element contamination is considered as a negative effect of industrial activities which must be monitored, assessed and managed (Alloway, 1995). For instance several authors have reported that soil contamination is accompanied by a loss of biodiversity, land cover and finally a lack of nutrients and water (Freitas et al., 2004; Mench and Baize, 2004; Zvereva and Kozlov, 2007). The exposure of plants to contaminants causes the same consequences as environmental stress and results in a lower biomass and lower vegetation (Zvereva and Kozlov, 2004). According to the international organization for standardization, the bioavailability of soil contaminants is defined as the fraction of available contaminant in the soil acquired by a target-organism through physiological processes (Harmsen, 2007). Consequently, the characterization and prediction of metal phytoavailability in soils is a crucial step for assessing the efficiency of soil remediation strategies such as the addition of soil amendments including organic matter (compost, farm manure and biosolids), lime or other alkaline materials (Oste et al., 2001; Lombi et al., 2003; Bolan et al., 2003; Brown et al. 2003; McBride, 1994; Puschenreiter et al., 2005; Ma et al., 2006) which have the capacity to adsorb, complex or (co)precipitate trace elements in the soil. 
Various treatments can be suggested or tested experimentally with a view to reducing the toxicity of a specific contaminated soil to plants by observing the growth or death of the plants. It is therefore of immense practical importance to be able to determine the optimal soil treatment with an amendment to a specific soil in order to reduce the soil toxicity which can be controlled and measured by metal concentrations in vegetation. It is usual to try to predict the effectiveness of these treatments, e.g. by how much the metal concentration will be reduced in plant leaves. One can specify a maximum allowable limit value (target) of metal concentration in a specific soil and seek to identify the corresponding optimal treatment to reduce the toxicity below the specified target. Examples of the areas where such predictive capability is of great value are the monitoring and management of industrial sites. Thus it is necessary to develop rapid and accurate prediction tools to control and analyze contamination sites and to manage soil use. This requires an extensive data bank of soil input-output data. However, measuring these parameters is time-consuming, difficult and expensive. In such cases, there is no clear standard rule for selection of the optimal soil treatment and one needs to determine the response of the soil. This is the so called inverse problem identification which must be solved to answer the following question: what are the controlled inputs (e.g. amendments) that have resulted in this given output (metal concentrations in the plant leaves). Recently, several applications based on inverse neural network models referred as (ANNi) were developed by several authors to optimize the performance of polygeneration systems parameters (Hernández et al., 2013), to control the strategy for absorption chillers (Labus et al, 2012), to optimize the operating conditions for compressor performance (Cortés et al., 2009), to optimize the operating conditions for heat and mass transfer in foodstuffs drying (Hernández, 2009), to predict the chemical oxygen demand removal during the degradation of alazine and gesaprim commercial herbicides (El hamzaoui et al., 2011) and to optimize solarassisted adsorption refrigeration system (Laidi and Hanini, 2013). 
The solution of the inverse problem has several practical applications in soil analysis, but has not been extensively studied so far, presumably due to the difficulties associated with the resolution of the nonlinear inverse problem. Over the last few years ANNs have been widely used in the field of soil science for the prediction of soil hydraulic properties (Schaap et al., 1998; Minasny et al., 2004), the generation of digital soil maps (McBratney et al., 2003; Behrens et al., 2005) and the modeling of the behavior of trace metals (Buszewski and Kowalkowski, 2006; Anagu et al., 2009 ; Gandhimathi and Meenambal, 2012). In this case, the ANN is trained to find these relations using an iterative calibration process. The ANN approach is beneficial compared to traditional regression methods if the input-output relationship is complex or unknown (Sarmadian and Taghizadeh Mehrjardi, 2008; Schaap and Leij, 1998; Hambli et al., 2006; Hambli, 2009). Moreover, ANN can be used as an inverse modeling approach. ANN modeling has been previously applied for solving inverse problems in other engineering fields (Jenkins, 1997; Rafiq et al., 2001; Hambli et al., 2006), but has.not been previously used in conjunction with soil analysis. Inverse ANNs have several advantages compared to other inverse identification techniques. First, ANNs are very general. It is proven that ANNs can accurately represent any sufficiently smooth nonlinear mapping (Jenkins, 1997; Rafiq et al., 2001). Second, the accuracy of the solution is independent of the number of inputs (Jenkins, 1997; Rafiq et al., 2001). This is an important point, because accurate prediction of the optimal soil treatment may require a large number of soil inputs. Third, ANNs are particularly useful in cases where solving the forward problem model is time-consuming (Hambli et al., 2006).

In this study, we have developed and tested an inverse artificial neural network (ANN) model for the prediction of optimal soil treatment to reduce toxicity assessed by a given target concentration of $\mathrm{Cu}$ in dwarf bean leaves (BL) from a given set of soil properties (inputs).

In order to prepare the training data for the inverse ANN, $16(4 \times 4)$ soil samples were collected from different soil profiles from a $\mathrm{Cu}$ sulfate and Chromated Copper Arsenate (CCA) 
contaminated site located in south-western France. The measured soil variables were soil pH, soil electrical conductivity (EC), dissolved organic carbon (DOC) and the concentration of $\mathrm{Cu}$ in $\mathrm{BL}$ grown in the laboratory on these contaminated soils treated with inorganic and organic amendments, with 4 replications for each measurement $(4 * 4$ measurements). The inverse ANN model was then developed and trained to predict the best soil treatment. The inputs were the soil $\mathrm{pH}, \mathrm{EC}, \mathrm{DOC}$, and a given target toxicity value of $\mathrm{Cu}$, whereas the output is the best treatment to reduce the given toxicity level.

In the studies of (Hernández, 2009; Cortés et al., 2009;; El hamzaoui et al., 2011; Labus et al, 2012; Hernández et al., 2013; Laidi and Hanini, 2013), the authors generated the resulting corresponding mathematical equations obtained from the trained direct ANNs representing the investigated processes behaviors and used optimization algorithms based on these equations to assess the optimal input parameters. In general, optimization involves finding the minimum or/and maximum of these $\mathrm{n}$ objective functions subjected to some constraints. For example in El Hamzaoui et al. (2011) study, the authors proposed an innovative methodology.to calculate the optimum operating conditions. In a first step, the explicit mathematical equation was obtained by the ANN after training (ANN weights) as an objective function using Matlab code. In a second step, the Nelder-Mead simplex method was applied to calculate the optimal (unknown) reaction time to obtain a chemical oxygen demand. Current inverse ANN differs from these previous works by two features: (i) The aim here was to predict an output as a non-numerical data (amendment type) where prediction of a minimum or a maximum response do not apply. And (ii) during the training phase, the amendment type was considered as an input which refers to a given amendment to reduce Copper toxicity in phytoremediated contaminated soils (Fig. 2). Therefore, the current inverse prediction do not requires the generation of the complicated ANN mathematical equations obtained from the trained direct ANNs. Two important aspects in the estimation of the optimal soil treatment from the measured soil inputs is the non-uniqueness of the 
solution of the inverse problem and the inaccuracies that may exist in the measurement of the soil inputs. The non-uniqueness of inverse solutions is a challenge for any inverse problem algorithm, because several solutions exist for the same inverse problem. The convergence of the solution may therefore be compromised. The second challenge is the inaccuracies that may exist in the actual measurements of soil inputs. The inverse ANN algorithm should be robust enough to be able to provide reasonable predictions of optimal soil treatment even when the soil input measurements are not perfectly accurate. Both challenges are addressed for the proposed inverse ANN algorithm. Results show that the inverse ANN model leads to a rapid and accurate prediction of the optimal soil treatment.

\section{Material and Methods}

From a practical point of view, the following three steps are required for the development of the inverse ANN model:

(i) Performing suitable experiments to measure the effects of selected soil inputs (properties, inorganic and organic amendments) on the soil toxicity assessed by concentration of $\mathrm{Cu}$ in dwarf BL.

(ii) Forward training the neural network based on the results of step (i) (mapping inputs to outputs).

(iii) Inverse ANN prediction (Prediction of the inputs given a target set of outputs).

The present section of the paper is divided into three sub-sections. The first sub-section presents the soil experiments. The second sub-section describes the inverse ANN approach and the third sub-section deals with the inverse ANN prediction considering the non-unique solutions of the inverse problem. 


\subsection{Soil sampling and preparation}

16 soil samples (four replicates) were collected from 16 plots $(1 \times 3 \mathrm{~m})$ from the BIOGECO phytostabilization platform installed on a former wood preservation site located in south-western France, Gironde County $\left(44^{\circ} 43^{\prime} \mathrm{N} ; 0^{\circ} 30^{\prime} \mathrm{W}\right)$, This site has been contaminated with high concentrations of $\mathrm{Cu}$. The history of the site and its characteristics are detailed in (Mench and Bes, 2009; Bes et al., 2010). Long-term aided phytostabilization experiments are established at the site. The plant communities cultivated in the zone of the field trial were Agrostis capillaris, Elytrigia repens, Rumex acetosella, Portulaca oleracea, Hypericum perforatum, Hypochaeris radicata, Euphorbia chamaescyce, Echium vulgare, Agrostis stolonifera, Lotus corniculatus, Cerastium glomeratum, and Populus nigra (Bes et al., 2010). Four different amendments were applied on the site and carefully mixed in the topsoil $(0-0.30 \mathrm{~m})$ with a stainless steel spade with four replicates: untreated soil (UNT), $0.2 \%$ of dolomite limestone (DL), $5 \%$ of compost of poultry manure and pine bark (CPM), and a mixture of $0.2 \%$ DL along with 5\% CPM (DLX CPM). Sixteen soil samples were collected from the topsoil of the platform, to a depth of $0.25 \mathrm{~m}$. One kilo of each soil was placed in a pot after sieving $(2 \mathrm{~mm})$. Four seeds of dwarf beans (Phaseolus vulgaris) were sown in all pots and cultivated for 18 days in controlled conditions (16 h light/ $8 \mathrm{~h}$ darkness regime). The soil moisture was maintained at around $50 \%$ of the field water capacity with additions of distilled water after weighing. Then the soil moisture was raised to $80 \%$ (11-13\% of air-dried soil mass) at the beginning of the germination stage of the seeds. At the end of the growing period the plants were harvested, and then the dry weight of BL was determined after drying at $70 \mathrm{C}^{\circ}$.

The BL were weighed $(35-150 \mathrm{mg})$ directly into Savillex Polytetrafluoroethylene PTFE 50mL vessels, $2 \mathrm{ml} \mathrm{H} \mathrm{H}_{2} \mathrm{O}$ and $2 \mathrm{~mL}$ supra-pure $14 \mathrm{M} \mathrm{HNO}_{3}$ were added and the vessels were heated open at $65 \mathrm{C}$ for 2 hours. Then the caps were closed and the containers were left overnight at $65 \mathrm{C}^{\circ}$ 
(12-14 h). After that they were opened, $0.5 \mathrm{~mL}$ of $\mathrm{H}_{2} \mathrm{O}_{2}(30 \%)$ was added to each sample and left at $75 \mathrm{C}^{\circ}$ open for 3 hours. Then $1.5+/-0.5 \mathrm{ml}$ of Fluorhydric Acid HF (48\%) was added to each sample, caps were closed and left at $100 \mathrm{C}^{\circ}$ overnight. Containers were opened and kept at $120 \mathrm{C}^{\circ}$ for 4-5 hours evaporating to dryness, taken off heat, $1 \mathrm{~mL} \mathrm{HNO}_{3}+5 \mathrm{ml} \mathrm{H} \mathrm{H}_{2} \mathrm{O}+0.1 \mathrm{ml} \mathrm{H}_{2} \mathrm{O}_{2}$ were added to each, gently warmed up and after cooling down made up to $50 \mathrm{ml}$. Mineral composition in BL was determined by ICP-MS (Varian 810-MS).

\subsection{Characterization of soil solution}

After harvesting the dwarf beans, the soils was watered with distilled water, and daily maintained at $80 \%$ of field capacity (11-13\% of air-dried soil mass) for 15 days. After 15 days three Rhizon soil-moisture samplers (SMS) from Rhizosphere Research Products (Wageningen, Holland) were inserted for $24 \mathrm{~h}$ with a $45^{\circ}$ angle into each potted soil ( $3 \times 16$ soils) to collect (30 $\mathrm{mL}$ ) soil pore water from each pot. Then dissolved organic carbon (DOC) was analyzed in the soil solution by a Shimadzu ${ }^{\odot}$ TOC 5000A analyzer. Soil $\mathrm{pH}$ and EC were determined in the same soil solution by $\mathrm{pH}$ meter and the electrical conductivity meter (EC).

\section{3. Neural network method}

The ANN architecture is composed of an input layer, a certain number of hidden layers and an output layer in forward connections. Each neuron in the input layer represents a single input parameter. These values are directly transmitted to the subsequent neurons of the hidden layers. The neurons of the last layer represent the ANN outputs (Fig. 1).

\section{Figure 1}


The output $y_{i}^{m}$ of neuron $i$ in a layer $m(m \geq 1)$ is calculated by (Jenkins, 1997; Rafiq et al., 2001; Hambli et al., 2006):

$$
\begin{aligned}
& y_{i}^{m}=f\left(v_{i}^{m}\right) \\
& v_{i}^{m}=\sum_{j=1}^{L} w_{j i}^{m-1} y_{j}^{m-1}+b_{i}^{m}
\end{aligned}
$$

where $y_{i}^{0}$ are the model inputs, $v_{i}^{m}$ are the outputs of the layer $m, f$ is the activation function, $L$ is the number of connections to the previous layer, $w_{j i}^{m-1}$ corresponds to the weights of each connection and $b_{i}^{m}$ is the bias, which represents the constant part in the activation function.

From among activation functions the sigmoid (logistic) function is the most usually employed in ANN applications. It is given by (Jenkins, 1997; Rafiq et al., 2001; Hambli et al., 2006):

$$
f\left(v_{i}^{m}\right)=\frac{1}{1+\exp \left(-\theta v_{i}^{m}\right)}
$$

where $\theta$ is a parameter defining the slope of the function $(\theta=0.9)$.

\subsubsection{Training algorithm}

The training process in ANNs involves presenting a set of examples (input patterns) with known outputs (target output) (Jenkins, 1997; Rafiq et al., 2001; Hambli et al., 2006; Hambli, 2009). The system adjusts the weights $w_{j i}^{m-1}$ of the internal connections to minimize errors between the network output and target output. There are several algorithms in an ANN and the one which was used here is the Levenberg-Marquardt back-propagation (BP) training algorithm. The BP algorithm is an iterative gradient algorithm designed to compute the connection weights by minimizing the total mean-square error between the actual output of the multi-layer network 
and the desired output. The knowledge is represented and stored by the strength (weights) of the connections between the neurons.

In the present work, an in-house ANN program called Neuromod written in Fortran (Hambli et al., 2006; Hambli, 2009) was applied. The basic ANN configuration employed in this study has one hidden layer with four neurons with a learning rate factor $\eta=0.1$ and momentum coefficient $\alpha=0.1$. Tests performed for more than one hidden layer and different $\eta$ and $\alpha$ parameters showed no significant improvement in the obtained results. The learning rate coefficient $\eta$ and the momentum term $\alpha$ are two user-defined BP algorithm training parameters that affect the learning procedure of the ANN. The training is sensitive to the choice of these net parameters. The learning rate coefficient employed during the adjustment of weights $\left(w_{j i}^{m-1}\right)$ was used to speed up or slow down the learning process. A larger learning coefficient increases the weight changes, hence large steps are taken towards the global minimum of error level, while smaller learning coefficients increase the number of steps taken to reach the desired error level.

To prepare the training data for the ANN, different measurements were performed on the four different soils subjected to four different treatments (UNT, DL, CPM and DLX CPM). The input factors and their minimum/maximum levels are given in Table 1.

\section{Table 1}

40 measurements were used for training, 16 samples for testing and 8 samples for validation. The testing data were not used for training. The testing data provided cross validation during the ANN training for verification of the network prediction accuracy. The validation data 
were used to measure the predictive capability of the ANN after complete training. In order to avoid data saturation, the input and the output variables were normalized between 0 and 1 using:

$$
x_{i}^{\text {norm }}=\frac{x_{i}-x_{i}^{\min }}{x_{i}^{\max }-x_{i}^{\min }}
$$

where $x_{i}, x_{i}^{\min }, x_{i}^{\max }$ and $x_{i}^{\text {norm }}$ denote respectively, the real input (output) variables value $i$, the minimum input (output) variable, the maximum input (output) variable and the normalized value $i$.

The real (de-normalized) value of the ANN was computed using:

$$
y_{t}=y_{\text {min }}+y_{\text {norm }}\left(y_{\text {max }}-y_{\text {min }}\right)
$$

where $y_{t}, y_{\min }, y_{\max }$ and $y_{\text {norm }}$ are the real-valued output variable, the minimum and maximum values of the real-valued output and the normalized output value from the ANN model respectively.

In the current study, we selected a limited number of independent soil parameters: soil $\mathrm{pH}, \mathrm{EC}$, soil solution DOC and a given target toxicity value of $\mathrm{Cu}$ concentration. The output is the optimal amendment to reduce the given toxicity level of $\mathrm{Cu}$.

It should be noted that the proposed ANN approach does not take into account all the possible factors which may influence soil toxicity. The prediction based on the ANN depends on the input pattern. Therefore, adding more inputs would lead to more accurate and reliable results.

The primary aim here was to illustrate the potential of the inverse neural network method to predict optimal soil amendment to reduce its toxicity rather than performing an investigation related to the effect of a larger number of soil inputs. 


\subsubsection{Selection of soil factors}

The correlations among soil variables may significantly affect the predictions of soil outputs. Care must therefore be taken concerning the selection of soil parameters. Although parameter correlations are observed and may be strong in some cases, existing soil analysis methods typically adopt the assumption of independent parameters (van der Zee and van Riemsdijk, 1987; Andersen and Christensen, 1988; Streck and Richter, 1997; Römkens and Salomons, 1998; Tiktak et al., 1998; Schaap and Leij, 1998; Elzinga et al., 1999; Annadurai and Lee, 2007; Sarmadian and Taghizadeh Mehrjardi, 2008; Schaap et al., 1998; Minasny et al., 2004; McBratney et al., 2003; Behrens et al., 2005; Buszewski and Kowalkowski, 2006; Anagu et al., 2009 ; Gandhimathi and Meenambal, 2012).

In this study, the soil inputs for the ANN model were limited to the three most influential independent factors (predictor variables) on the mobility and availability of metals in the soil:

- Soil pH: Kabata-Pendias and Pendias. (2000) and Jackson and Miller. (2000) reported that the addition of amendments to soil increased the soil $\mathrm{pH}$ compared to the untreated soil, leading to a reduction in the mobility and the availability of metals to plants.

- DOC: Hsu and Lo. (2000) noted that the addition of amendment to the soil increased the DOC soil contents compared to that of untreated soil, which leads to increasing the plant mass, reducing the bio availability of metals by forming ligands with the dissolved organic matter.

- EC: Du Laing et al., (2008, 2009) and Hatje et al., (2003) found that an increase in conductivity (salinity) led to an increase in the mobility of some metals such as cadmium and zinc, thereby increasing the availability and the bioavailability of these metals to the plant. 
Correlative models such as ANNs are applied to approximate various complex engineering problems. Model development starts with the determination of the parameters which have the greatest influence on the model results. Sensitivity analyses can be performed to determine: (1) which parameters require additional future research; (2) which parameters are insignificant and can be eliminated from the final model; (3) which inputs contribute most to output variability; (4) which parameters are the most highly correlated with the output, and (5) once the model is in production use, what consequence results from changing a given input parameter (Hamby, 1993). The model parameters that exert the greatest influence on the model results are identified through a sensitivity analysis. In our case, the correlations among soil variables may significantly affect the predictions. In such a case, decomposition methods can be used to reduce the prediction sensitivity (Jacques et al., 2006).

\subsection{Inverse neural network for inverse prediction}

In general, standard 'forward mapping' using ANN involves nonlinear mapping from the space of the soil inputs to the soil outputs (toxicity). The inverse of forward mapping goes backward in time. Given a certain soil target response, the inverse prediction based on 'backward mapping' determines the set of soil inputs that has resulted in the given soil outputs, thereby mapping the space of soil outputs to the space of soil inputs (Fig. 2).

\section{Figure 2}

It is mathematically proven that a feed forward ANN with at least one hidden layer, $n$ hidden neurons, and sigmoid activation functions can approximate any continuous function with an integrated squared error regardless of the dimension of the input space (Barron, 1993). 


\subsubsection{Non-uniqueness and robustness of the inverse ANN model}

The non-uniqueness of the solution is an important challenge for all inverse identification methods because several solutions exist for the same inverse problem. In the current work, we assign a search interval $\left(\Delta Y_{t}\right)$ to the given target soil output (toxicity) $\left(Y_{t}\right)$ and the inverse ANN was designed to automatically identify via iterative loops all the corresponding inputs which generate outputs located within the interval $\Delta Y_{t}$.

A second challenge is that the measurements of soil inputs and corresponding outputs are not noise-free. It is therefore important that the inverse ANN model be robust enough to handle the noise that will exist in actual soil measurements. In the current work, to ensure the robustness of the inverse ANN, the trained ANN was tested using noisy output data in the form:

$$
Y_{t}^{n}=Y_{t}+f\left(0, Y_{t} / \lambda\right)
$$

where $Y_{t}^{n}$ denote respectively the noisy output, $f\left(0, Y_{t} / \lambda\right)$ is the standard Gaussian distribution function (mean value: $\mu=0$ and standard deviation: $\sigma=Y_{t} / \lambda$ ). The signal to noise ratio is represented by $Y_{t} / \lambda$.

\section{Results and Discussion}

The inverse ANN was trained with $5.10^{5}$ epochs. The training performance was assessed by the root mean square error (RMSE). At the end of the training phase, the RMSE convergence value was 1.E-5. The inverse ANN was then tested without considering the noisy dataset:

(i) First, the direct ANN was applied to 300 testing combinations of soil inputs to predict the optimal soil amendments (considered as the reference values by the direct ANN prediction).

(ii) Then, the inverse ANN was applied to predict the optimal soil amendment related to these 300 testing combinations. 
(iii) The results generated by the inverse ANN in step (ii) were compared to the direct ANN results of step (i)

Figure 3 shows the variation of the inverse predicted optimal amendments versus the reference ones. The integers $1,2,3$ and 4 refer to UNT, CPM, DL and DLX CPM soil amendments respectively.

\section{Figure 3}

It was found that the ANN is sensitive to noise and gives inaccurate output predictions when the input dataset is slightly noisy. It can be noticed that the simulations generated solutions composed of mixed amendments as optimal treatment (non-integer values in the curve denote mixed amendments). For example 1.5 represents a $50 \%$ mix of 1 (UNT) and 2 (CPM). In previous studies, numerous amendments have been incorporated into soils polluted with metal (metalloids) to immobilize pollutants. These amendments include individual additions of amendments (Walker et al., 2004; Schwab et al., 2007; Derome, 2009; González-Alcaraz et al., 2011; Melamed et al., 2003; Brown et al., 2005; Ford, 2002; Trivedi and Axe, 2001; Hartley and Lepp, 2008; Gupta and Sharma., 2002; Garau et al., 2011; Brown et al., 2003; Torri and Lavado, 2008) and combinations of different amendments including organic and liming materials (Alvarenga et al.,2008; Farrell and Jones, 2010; Bes and Mench, 2008), iron oxides and lime (Warren and Alloway, 2003) and compost and iron oxide (Gadepalle et al., 2008).

In order to reduce the sensitivity of the inverse ANN to noise, the training algorithm was modified by introducing noise to the training and validation datasets (Eq. 6) with signal to noise ratios between 100 and 5 (Fig. 4). It was found that when ANNs are trained using noisy datasets, they are very robust and work well even when the input and output values are noisy. As depicted 
in Fig. 4, the accuracy of the inverse ANN prediction decreases when the signal to noise ratio $(\lambda)$ decreases (lower $\mathrm{R}^{2}$ value). However, the reduction in accuracy with the increase in noise is gradual and simply reflects the lower quality of the measurement data. This result indicates that the inverse ANN model was able to predict accurately the optimal soil treatment corresponding to a target value of $\mathrm{Cu}$ concentration in the BL.

\section{Figure 4}

Because of the noise (uncertainty) concerning the input measurements which can be characterized by a given set of scattered input data with a measured statistical distribution (mainly a mean and standard deviation), robust processing of scattered data methods is needed to predict reliable responses. Using the inverse ANN model developed, this can be performed based on a three-stage analysis:

(i) Perform simple input-output predictions on the scattered data set to obtain initial measures of output variations. This evaluation does not account for statistical noise.

(ii) Generate stochastic data based on the mean value and the standard deviation and perform a stochastic prediction.

(iii) Estimate the sensitivity of the stochastic results of (ii) in relation to the results of (i) and assess the impact of the input sensitivities on the response.

In this way, a confidence interval can be estimated related to the data noise. Note that enhanced data smoothing procedures can be applied in order to identify general trends by removing the background noise of random variability often present in raw data and to increase the prediction accuracy (Velleman, 1980; Kafadar, 1994). There are a number of smoothing algorithms including histograms, nearest-neighbor, kernel and regression smooths. The selection of a suitable procedure depends mainly on its robustness to treat the scatter, its speed and its interpretation. 
In order to test the capability of the trained inverse ANN to predict the optimal treatment, the model was run for different combinations of soil inputs. The input parameters were soil $\mathrm{pH}$, soil EC and DOC inputs and target $\mathrm{Cu}$ concentration. For each input factor, four values in the interval of its min and max value were applied here to capture the non linear soil response (Table 2).

$256(4 \times 4 \times 4 \times 4)$ full factorial combinations of the inputs were computed with the trained inverse ANN with a total computation time of about 2 seconds.

\section{Table 2}

Figure 5 shows the predicted optimal treatment for soil corresponding to a target value of $\mathrm{Cu}$ concentration in $\mathrm{BL}$ of $150 \mathrm{mg} \cdot \mathrm{kg}^{-1}$. The non-uniqueness of the solution related to the effects of soil $\mathrm{pH}$ and $\mathrm{DOC}$ can be observed corresponding to the target $\mathrm{Cu}$ concentration indicated by the vertical dashed line $(\lambda=50)$.

\section{Figure 5}

The results show the dependence between the soil properties (selected inputs in the current case) and the optimal treatment of the soil to reduce the $\mathrm{Cu}$ plant toxicity (case of $150 \mathrm{mg} \cdot \mathrm{kg}^{-1}$ ). One can see in the (UNT, CPM, DLX CPM) soils that increasing the soil $\mathrm{pH}$ leads to a lower concentration of $\mathrm{Cu}$ in the bean leaves at the same level of (DOC), while the opposite effect can be observed in the soil treated with (DL).

It can be seen that the acidity and the level of DOC in the untreated soil significantly affect the $\mathrm{Cu}$ concentration in the bean leaves compared to the untreated soils. Predicted results show that the addition of CPM, DL and DLX CPM amendments to the soil decrease the effect of the 
soil $\mathrm{pH}$ on the concentrations of $\mathrm{Cu}$ in the bean leaves whatever the quantity of DOC in the soil solution.

The plots on Fig. 5 show that the best amendment for decreasing the concentration of $\mathrm{Cu}$ in the bean leaves under the effect of the selected input factors ( $\mathrm{pH}, \mathrm{DOC}$, and $\mathrm{EC}$ ) and for a given target value of $\mathrm{Cu}$ in the $\mathrm{BL}\left(150 \mathrm{mg} \cdot \mathrm{kg}^{-1}\right)$ is the $\mathrm{CPM}$ which generated a significant reduction in $\mathrm{Cu}$ concentrations in the BL compared to the other treatments. CPM reduced the concentrations of $\mathrm{Cu}$ in the BL to less than $200 \mathrm{mg} \cdot \mathrm{kg}^{-1}$, followed by the soil treated with DL (concentrations of about $270 \mathrm{mg} \cdot \mathrm{kg}^{-1}$ ), then the soil treated with the DLX CPM (concentrations of almost $285 \mathrm{mg} \cdot \mathrm{kg}^{1}$ ), while the $\mathrm{Cu}$ concentrations in the UNT soil reached a maximum value of about 300 mg. $\mathrm{kg}^{-1}$ for a soil $\mathrm{pH}$ of 7 and less than $150 \mathrm{mg} \cdot \mathrm{kg}^{-1}$ for a soil $\mathrm{pH}$ of 7.3 . This result suggests that soil $\mathrm{pH}$ must be assessed accurately for the optimal monitoring of soil $\mathrm{Cu}$ toxicity.

Our predicted results agree with the results of Harter and Naidu (1995) who explained this observation by the capacity of CPM in the soil to retain soil metals.

The bioavailability of $\mathrm{Cu}$ in the soil is considered as the part of the metal which is found free in the solution, i.e. not complexed with organic species nor adsorbed to the soil solid fractions (Zhang et al., 2001). The binding of the metal to the organic fraction depends on the total number of both strong and weak binding sites, which is related to the number of functional groups. The total acidity e.g. the number of carboxylic acid and phenol hydroxyl groups is often used as a measurement of binding capacity (Gerke, 1994). Sauvé et al. (2000) reported that the availability of soil metals to the plants depends on two factors: (i) the presence of several sorbents in the soil such as organic matter, and (ii) the physico-chemical parameters such as $\mathrm{pH}$ and ionic strength. Kabata-Pendias and Pendias (1992), Lexmond (1980), McBride (1989), Tyler and Olsson (2001) reported that the bioavailability and toxicity of $\mathrm{Cu}$ in the soil is increased in acidic soil relative to calcareous soil. This increase is due to the increase in the concentration of $\mathrm{Cu}^{+2}$ (free Copper) in the soil solution which generally presents the available form of $\mathrm{Cu}$ to the living organisms in the 
soil (plants, microorganisms). The increase in the soil $\mathrm{pH}$ leads to an increase in the binding of $\mathrm{Cu}$ to the soil constituents (McLaren and Crawford, 1973) and therefore decreases the mobility and availability of soil $\mathrm{Cu}$. Brown et al. (2003) found that the addition of organic amendments to the soil such as compost, farmyard manure and biosolid compost reduced the availability of trace metals in soils due to the high content of organic matter, P and Fe. Balasoiu et al. (2001) reported that the organic matter of soils can bind significant amounts of $\mathrm{Cu}$ by forming an $\mathrm{OM}-$ bound $\mathrm{Cu}$ fraction which represents about $96 \%$ of the total $\mathrm{Cu}$ in CCA-contaminated soil.

Figure 6 shows the predicted optimal treatments for the soil in the form of a ternary (triangular) plot corresponding to different target values of $\mathrm{Cu}$ concentration in $\mathrm{BL}$ and soil $\mathrm{pH}$, EC and DOC interactions $(\lambda=50)$. The ternary diagram is a graph that shows the response of three combined variables $(\mathrm{pH}, \mathrm{EC}$ and $\mathrm{DOC})$ as a position in an equilateral triangle. Such diagrams can be used for graphical classification and interpretation of soil responses. The advantage of using a ternary plot for depicting compositions is that the three variables can be conveniently plotted in a two-dimensional graph. Every point on a ternary plot represents a different composition of the three components. It can be used for soil treatment classification schemes.

\section{Figure 6}

The ternary diagram indicates that the UNT soil is the best treatment to reduce toxicity below the target $\mathrm{Cu}$ value of $150 \mathrm{mg} \cdot \mathrm{kg}^{-1}$ corresponding to a soil $\mathrm{pH}$ greater than 7.3 combined with soil EC greater than $140 \mu \mathrm{S} . \mathrm{cm}^{-1}$ (red crosses) (Fig. 6-a) independent of the DOC value. For lower values of soil EC and of $\mathrm{pH}$ (7.1), only the CPM treatment is able to reduce the toxicity (black circles) (note the empty region in Fig. 6-a).

When the target $\mathrm{Cu}$ value is increased to $200 \mathrm{mg}^{\mathrm{kg}}{ }^{-1}$ (Fig. 6- b), the inverse ANN predicted the same results but with a larger region in the plot, indicating that the UNT is the most suitable to reduce toxicity for a soil $\mathrm{pH}$ higher than 7.2. The CPM treatment is able to reduce the 
toxicity (black circles) whatever the values of $\mathrm{pH}, \mathrm{EC}$ and DOC. Note that DL and DLX CPM are unable to reduce the target $\mathrm{Cu}$ toxicity below $200 \mathrm{mg} \cdot \mathrm{kg}^{-1}$ whatever the values of $\mathrm{pH}$, EC and DOC.

For a target $\mathrm{Cu}$ value of $250 \mathrm{mg} \cdot \mathrm{kg}^{-1}$ (Fig. 6-c), the predicted results reveal that the UNT soil domain remains unchanged (saturation), indicating that UNT soil is unable to reduce the toxicity outside the range $\left(\mathrm{pH}<7.2\right.$ and $\left.\mathrm{EC}<140 \mu \mathrm{S} . \mathrm{cm}^{-1}\right)$. The CPM treatment is able to reduce the toxicity (black circles) whatever the values of $\mathrm{pH}, \mathrm{EC}$ and DOC. It can also be seen that the DL treatment (blue triangles) is able to reduce the toxicity below a $\mathrm{Cu}$ value of $250 \mathrm{mg} \cdot \mathrm{kg}^{-1}$ in the range of $\left(\mathrm{DOC}<35 \mathrm{mg} . \mathrm{l}^{-1}\right.$ and $\left.\mathrm{EC}>140 \mu \mathrm{S} . \mathrm{cm}^{-1}\right)$. Finally, for a larger target value of $\mathrm{Cu}(300$ mg.kg ${ }^{-1}$ ) (Fig. 6-d), all four treatments are able to sreduce the toxicity except in the case of UNT soil for $\mathrm{EC}<140 \mu \mathrm{S} . \mathrm{cm}^{-1}$.

The ternary diagram shows that among the four treatments, CPM leads to the best results (covering the largest region in the plots). Nevertheless, the other treatments can be considered as optimal choices for particular cases depending on the combinations of the $\mathrm{pH}$, EC and DOC values.

\section{Conclusions}

The current study demonstrated that inverse ANN can be used as a reliable and rapid tool to optimize the selection of the optimal amendment for a given soil characteristics. The inverse ANN was proven recently to be efficient tool to optimize several processes (Hernández, 2009; Cortés et al., 2009;; El hamzaoui et al., 2011; Labus et al, 2012; Hernández et al., 2013; Laidi and Hanini, 2013). Nevertheless, applications of such ANN based optimization procedure are still lacking in the field of soil/plant problems. 
In general, several models have been developed to predict the relationship between soil input parameters and design performance of ANNs. Generally, two methods are used to develop prediction models: conventional mathematical methods and ANN. It has been reported that ANNs provided superior predictive performance when compared with conventional mathematical methods including multiple linear regression (MLR models) (van der Zee and van Riemsdijk, 1987; Andersen and Christensen, 1988; Streck and Richter, 1997; Römkens and Salomons, 1998; Tiktak et al., 1998; Schaap and Leij, 1998; Elzinga et al., 1999; Annadurai and Lee, 2007; Sarmadian and Taghizadeh Mehrjardi, 2008). In addition, when MLR methods are used, the relationships between soil inputs and design outputs have to be stated a priori in the regression models. In many situations in soil engineering, the input-output relationships are highly complex and are poorly understood. The lack of physical understanding and of a powerful general tool for mathematical modeling leads to either simplifying the problem or incorporating several assumptions into the mathematical models. Consequently, many mathematical models fail to simulate the complex behavior of most soil engineering problems. In contrast, ANNs are based on the data alone where such relationships do not need to be formulated beforehand (Schaap et al., 1998; Minasny et al., 2004; McBratney et al., 2003; Behrens et al., 2005; Buszewski and Kowalkowski, 2006; Anagu et al., 2009; Gandhimathi and Meenambal, 2012). Moreover, ANNs can be used at research level as a method to determine the most important parameters in a design that could then be used to formulate a mechanistic model and to determine where future research efforts should be targetted. The results of ANN testing (prediction) allow for the investigation of the soil factors' interactions. This methodology could therefore be effectively used to study the importance of individual, cumulative and interactive effects of the selected soil inputs in the phytoremediation of contaminated soil measured by metal concentrations in vegetation. The effect of several soil treatments and their combinations can also be investigated. For example, the proposed inverse ANN model generated solutions composed of mixed amendments as the optimal 
treatment (Fig. 3) which is in agreement with previous studies where the authors applied individual combinations of different amendments (Alvarenga et al.,2008; Farrell and Jones, 2010; Warren and Alloway, 2003; Gadepalle et al., 2008; Bes and Mench, 2008). The present study showed that a plausible innovative low-cost strategy for the optimal remediation of contaminated soils in situ could be performed using such inverse ANN approaches.

The effects of noise on the performance of the ANN were also investigated. Noise was introduced to the training data points and the inverse ANN was trained using noisy inputs. It was observed that the proposed modification in the training algorithm makes the ANN very robust against noisy density measurements. It was shown that the ANN works reasonably well even when both non-uniqueness and noise are taken into account.

Despite their good performance in many situations, ANNs suffer from a number of limitations. First, they are not able to explain the physical relationships between the input-output data. Second, there are no general guidelines which can help in the design of the ANN architecture for a given problem.

The primary aim of the current study was to illustrate the potential of the inverse neural network method as an alternative to traditional mathematical models to predict the optimal soil amendment to reduce soil toxicity. The inverse problem (going from the target $\mathrm{Cu}$ level and soil properties to the best amendment for reducing soil toxicity) has not a unique solution. The inverse ANN developed was specially designed for the prediction of non-unique optimal soil treatments. The ANN method can potentially be applied with a high level of success in the phytoremediation of contaminated soils. Before its large-scale application, however, further investigations are needed by performing: (i) experimental validation based on several experiments including additional factors to capture complex soil behavior, (ii) a sensitivity analysis to check the reliability of the inverse ANN and (iii) enhanced data smoothing procedures in order to identify 
general trends by removing the background noise of random variability often present in raw data and to increase the prediction accuracy.

\section{Acknowledgments}

Author thank Mrs Audrey Dufour (Cetrahe, University of Orléans, France) for the analysis of major cations and anions in the soil pore water and Dr Stanislas Strekopytov (Natural History Museum, London, UK) for the digestion of plants and subsequent mineral analysis. The authors are grateful to Prof. Mench M. for providing the soil samples and to ADEME, Department of Urban Browfields and Polluted Sites, Angers, France and the European Commission under the Seventh Framework Program for Research (FP7KBBE-266124, GREENLAND) for financial support of the BIOGECO phytoremediation platform.

\section{References}

Adriano, D.C., 2001. Trace elements in terrestrial environments; Biochemistry. bioavailability and risks of metals. Springer-Verlag. New York.

Alloway, B.J., 1995. Heavy metals in soils. Chapman and Hall. London. 368p.

Alvarenga, P., Palma P., Goncalves A.P., Fernandes R.M., de Varennes A., Vallini G., Duarte E., Cunha-Queda A.C., 2008. Evaluation of tests to assess the quality of mine contaminated soils. Environmental Geochemistry and Health 30 95-99.

Anagu, I., Ingwersen J., Utermann, J., Streck T., 2009. Estimation of heavy metal sorption in German soils using artificial neural networks Geoderma, 152 104-112.

Andersen, P.R., Christensen, T.H., 1988. Distribution coefficients of $\mathrm{Cd}, \mathrm{Co}, \mathrm{Ni}$ and $\mathrm{Zn}$ in soils. Journal of Soil Science. 39, 15-22. 
Annadurai, G., Lee, J.F., 2007. Application of artificial neural network model for the development of optimized complex medium for phenol degradation using seudomonas pictorum (NICM 2074)", Biodegradation.18:383-392.

Balasoiu, C.F., Zagury, G.J., Deschênes, L., 2001. Partitioning and speciation of chromium. Copper. and arsenic in CCA-contaminated soils: influence of soil composition. The Science of the Total Environment. 280 (1-3). pp. 239-255.

Barron, A.R., 1993. Universal approximation bounds for superpositions of a sigmoidal function. IEEE Transactions on Information Theory 39: 930-945.

Behrens, T., Förster, H., Scholten, T., Steinrüken, U., Spies, E., Goldschmitt, M., 2005. Digital soil mapping using artificial neural networks. Journal of Plant Nutrition and Soil Science.168, 21-33.

Bes, C.M., Mench, M., 2008. Remediation of copper-contaminated top soils from a wood treatment facility using in situ stabilization. Environnemental Pollution;156:1128-38.

Bes, C.M., Mench, M., Aulen, M., Gaste, H., Taberly, J., 2010. Spatial variation of plant communities and shoot $\mathrm{Cu}$ concentrations of plant species at a timber treatment site. Plant Soil; 330:267-80.

Bolan, N.S., Adriano, D.C., Natesan, R., Koo, B.J., 2003. Effects of organic amendments on the reduction and phytoavailability of chromate in mineral soil. Journal of Environmental Quality 32. 120-128.

Brown, S., Christensen B., Lombi E., McLaughlin M., McGrath S., Colpaert J., Vangronsveld J., 2005. An inter-laboratory study to test the ability of amendments to reduce the availability of $\mathrm{Cd}, \mathrm{Pb}$ and $\mathrm{Zn}$ in situ. Environnemental Pollution. 138 34-45.

Brown, S.L., Henry, C.L., Chaney, R., Compton, H., DeVolder, P.S., 2003. Using municipal biosolids in combination with other residuals to restore metal-contaminated mining areas. Journal of Plant and Soil. 249 , 203-215. 
Buszewski, B., Kowalkowski, T., 2006. A new model of heavy metal transport in the soil using non-linear artificial neural networks. Journal of Environmental Engineering and Science. 23 (4), 589-595.

Cortés, O., Urquiza, G., Hernández, J.A., 2009. Optimization of operating conditions for compressor performance by means of neural network inverse, Applied Energy 86, 24872493.

Derome, J., 2009. Detoxification and amelioration of heavy metal contaminated forest soils by means of liming and fertilization. Environnemental Pollution. 107, 79-88.

Du Laing, G., De Vos, R., Vandecasteele, B., Lesage, E., Tack, F.M.G., Verloo, M.G., 2008. Effect of salinity on heavy metal mobility and availability in intertidal sediments of the Scheldt estuary. Estuarine, Coastal and Shelf Science, 77, 589-602.

Du Laing, G., Van de Moortel, A., Moors, W., De Grauwe, P., Meers, E., Tack, F., Verloo, M., 2009. Factors affecting metal concentrations in reed plants (Phragmites australis) of intertidal marshes in the Scheldt estuary. Ecological Engineering. 35, 310318.

El Hamzaoui, Y., Hernández, J.A., Silva-Martínez, S., Bassam, A., Álvarez, A., Lizama-Bahena, C., 2011. Optimal performance of COD removal during aqueous treatment of alazine and gesaprim commercial herbicides by direct and inverse neural network, Desalination 277, $325-337$.

Elzinga, E.J., Van Grinsven, J.J.M., Swartjes, F.A., 1999. General purpose Freundlich isotherms for cadmium, copper and zinc in soils. European Journal of Soil Science. 50, 139-149.

Farrell, M., Jones, D.L., 2010. Use of composts in the remediation of heavy metal contaminated soil. Journal of Hazardous Materials. 175 575-582.

Ford, R.G., 2002. Rates of hydrous ferric oxide crystallization and the influence on coprecipitated arsenate. Environmental Science \& Technology. 36 2459-2463. 
Freitas, H., Prasad, M. N. V., Pratas, J., 2004. Plant community tolerant to trace elements growing on the degraded soils of Sao Domingos mine in the south east of Portugal: environmental implications. Environment International., 30, 65-72.

Gadepalle, V.P., Ouki S.K., Herwijnen R.V., Hutchings, T., 2008. Effects of amended compost on mobility and uptake of arsenic by rye grass in contaminated soil, Chemosphere 72 10561061.

Gandhimathi, A., Meenambal, T., 2012. Analysis of Heavy Metal for Soil in Coimbatore by using ANN Model, European Journal of Scientific Research, Vol.68 No.4, pp. 462-474.

Garau, G., Silvetti M., Deiana S., Deiana P., Castaldi, P., 2011. Long-term influence of red mud on As mobility and soil physico-chemical and microbial parameters in a polluted sub-acidic soil. Journal of Hazardous Materials. 185 1241-1248.

Gerke, J., 1994. Aluminium complexation by humic substances and aluminium species in the soil solution. Geoderma. 63:165-175.

González-Alcaraz, M.N., Conesa H.M, Tercero M.C, Schulinb R., Álvarez-Rogel J., Egea C., 2011. The combined use of liming and Sarcocornia fruticosa development for phytomanagement of salt marsh soils polluted by mine wastes. Journal of Hazardous Materials. 186 805-813.

Gupta, V.K., Sharma S., 2002. Removal of cadmium and zinc from aqueous solutions using red mud. Environmental Science \& Technology. 36 3612-3617.

Hambli, R., 2009. Statistical damage analysis of extrusion processes using finite element method and neural networks simulation. Finite Elements in Anal and Design. (45), 10, 640-649.

Hambli, R., Chamekh, A., Bel Hadj Salah, H., 2006. Real-time deformation of structure using finite element and neural networks in virtual reality applications. Finite Elements in Analysis and Design, 42, Issue: 11, pp: 985-991. 
Hamby, D.M., 1993. A Probabilistic Estimation of Atmospheric tritium Dose. Health Physicians. $65,33--40$.

Harmsen, J., 2007. Measuring bioavailability: from a scientific approach to standard methods. Journal of Environmental Quality. 36, 1420- 1428.

Harter, R.D., Naidu, R., 1995. Role of metal-organic cCPMplexation in metal sorption by soils. Advances in Agronomy. 55. 219-263.

Hartley, W., Lepp, N.W., 2008. Remediation of arsenic contaminated soils by iron-oxide application, evaluated in terms of plant productivity, arsenic and phytotoxic metal uptake, Science of total Environment. 390 35-44.

Hatje, V., Payne, T.E., Hill, D.M., McOrist, G., Birch, G.F., Szymczak, R., 2003. Kinetics of trace element uptake and release by particles in estuarine waters: effects of $\mathrm{pH}$, salinity, and particle loading. Environment International, 29 , pp. 619-629.

Hernández, J.A., 2009. Optimum operating conditions for heat and mass transfer in foodstuffs drying by means of neural network inverse, Food Control 20, 435-438.

Hernández, J.A., Colorado, D., Cortés-Aburto, O., El Hamzaoui, Y., Velazquez, V., Alonso, B., 2013. Inverse neural network for optimal performance in polygeneration systems, Applied Thermal Engineering 50, 1399-1406.

Hsu. J.H., Lo, S.L., 2000. Characterisation and extractability of copper. manganese. and zinc in swine manure composts. Journal of Environmental industry. Environmental Pollution. 101. $43-48$.

Jackson, B.P., Miller, W.P., 2000. Soil solution chemistry of a fly ash-. poultry litter-. and sewage sludge-amended soil. Journal of Environmental Quality. 29 (2). pp. 430-436

Jacques, J., Lavergne, C., Devictor, N., 2006. Sensitivity analysis in presence of model uncertainty and correlated inputs. Reliability Engineering \& System Safety 91,1126-1134. 
Jenkins, W. M., 1997. An introduction to neural computing for the structural engineer, Journal of Structural Engineering, 75 3, 38-41.

Kabata-Pendias, A., Pendias, H., 1992. Trace elements in soils andplants. 2nd ed. CRC Press, Inc, Boca Raton, Florida, pp. 365.

Kabata-Pendias, A., Pendias, H., 2000. Trace Elements is Soils and Plants. CRC Press, Boca Raton, Florida, USA.

Kafadar, K., 1994. Choosing among two-dimensional smoothers in practice', Computational Statistics and Data Analysis, 18, 419\}439.

Labus, J., Hernández, J.A., Bruno, J.C., Coronas, A., 2012. Inverse neural network based control strategy for absorption chillers, Renewable Energy 39, 471-482.

Laidi, M. and Hanini, S., 2013. Optimal solar COP prediction of a solar-assisted adsorption refrigeration system working with activated carbon/methanol as working pairs using direct and inverse artificial neural network, International Journal of Refregeration, 36, 247 -257.

Lexmond, M., 1980. The effect of soil $\mathrm{pH}$ on copper toxicity to forage maize grown under field conditions. Netherlands Journal of Agricultural Science. 28, 164-184.

Lombi, E., Hamon, R.E., McGrath, S.P., McLaughlin, M.J., 2003. Lability of Cd, Cu, and Zn in polluted soils treated with lime, beringite, and red mud and identification of a non labile colloidal fraction of metals using isotopic techniques. Environmental Science and Technology.37 (5), 979-984.

Ma, Y., Lombi, E., Oliver, I., Nolan, A., McLaughlin, M., 2006. Long-term aging of copper added to soils. Environmental Science and Technology 40, 6310-6317.

McBratney, A.B., Mendoca Santos, M.L., Minasny, B., 2003. On digital soil mapping. Geoderma $117,3-52$.

McBride, M. B., 1989. Reactions controlling heavy metal solubility in soils. Advances in Soil Sciences. 10, 156. 
McBride, M.B., 1994. Environmental Chemistry of Soils. Oxford University Press, New York, NY.

McLaren, R. G., Crawford, D. V., 1973. Studies on soil copper. II. The specific adsorption of copper by soils. Journal of soil science. $24,443-452$.

Melamed, R., Cao X., Chen, M., Ma, L.Q., 2003. Field assessment of lead immobilization in a contaminated soil after phosphate application. Science of the Total Environment. 305 117127.

Mench, M., Bes, C., 2009. Assessment of ecotoxicity of topsoils from a wood treatment site. Pedosphere; 19:143-55.

Mench, M., Baize, D., 2004. Contamination des sols et de nos aliments d'origine végétale par les éléments en traces. Cour. Environ. INRA (in French). 52: 31-56.

Minasny, B., Hopmans, J.W., Harter, T., Eching, S.O., Tuli, A., Denton, M.A., 2004. Neural networks prediction of soil hydraulic functions for alluvial soils using multistep outflow data. Soil Science Society of America Journal. 68, 417-429.

Oste, L.A., Dolfing, J., Ma,W.C., Lexmond, T.M., 2001. Effect of beringite on cadmium and zinc uptake by plants and earthworms: more than a liming effect. Environmental Toxicology and Chemistry. 20 (6), 1339-1345.

Puschenreiter, M., Horak, O., Friesl, W., Hartl, W., 2005. Low cost agricultural measures to reduce heavy metal transfer into the food chain - a review. Plant and Soil Environment . 51 (1), 1-11.

Rafiq, M. Y., Bugmann, G., Easterbrook D. J., 2001. Neural network design for engineering applications. Computers and Structures, Vol. 79, (17), 1541-1552.

Römkens, P.F.A.M., Salomons, W., 1998. Cd, Cu and $\mathrm{Zn}$ solubility in arable and forest soils: consequences of land use changes for metal mobility and risk assessment. Soil Science. 163, 859-871. 
Sarmadian, F., Taghizadeh Mehrjardi, R., 2008. Modeling of Some Soil Properties Using Artificial Neural Network and Multivariate Regression in Gorgan Province, North of Iran. Global Journal of Environmental Research 2 (1): 30-35.

Sauve', S., Hendershot, W., Allen H. E., 2000. Solid-solution partitioning of metals in contaminated soils: dependence on $\mathrm{pH}$, total metal burden, and organic matter. Environmental Science \& Technology. 34, 1125-1131.

Schaap, M.G., F.J. Leij., 1998. Using neural networks to predict soil water retention and soil hydraulic conductivity. Soil and Tillage Research, 47: 37-42.

Schaap, M.G., Leij, F.J., van Genuchten, M.T., 1998. Neural networks analysis for hierarchical prediction of soil hydraulic properties. Soil Science Society of America Journal. 62, 84-855.

Schwab, P., Zhu D., Banks M.K., 2007. Heavy metal leaching from mine tailings as affected by organic amendments. Bioresource Technology. 98, 2935-2941.

Streck, T., Richter, J., 1997. Heavy metal displacement in a sandy soil at the field scale: I. Measurements and parameterization of sorption. Journal of Environmental Quality. 26, 4956.

Tiktak, A., Alkemade, J.R.M., Van Grinsven, J.J.M., Makaske, G.B., 1998. Modeling cadmium accumulation at a regional scale in the Netherlands. Nutrient Cycling in Agroecosystems. 50, 209-222.

Torri S.I., Lavado R.S., 2008. Dynamics of $\mathrm{Cd}, \mathrm{Cu}$ and $\mathrm{Pb}$ added to soil through different kinds of sewage sludge, Waste Management. 28, 21-832.

Trivedi, P., Axe L., 2001. Predicting divalent metal sorption to hydrous Al, Fe, and Mn oxides. Environmental Science \& Technology. 35, 1779-1784.

Tyler, G., Olsson, T., 2001. Concentrations of 60 elements in the soil solution as related to the soil acidity. European Journal of Soil Science. 52, 151-165. 
van der Zee, S.E.A.T.M., van Riemsdijk,W.H., 1987. Transport of reactive solute in spatially variable soil systems. Water Resources Research. 23, 2059-2069.

Velleman, P. F., 1980. Definition and comparison of robust nonlinear data smoothing algorithms'. Journal of the American Statistical Association, 75, 609-615.

Walker, D.J., Clemente R., Bernal M.P., 2004, Contrasting effects of manure and compost on soil $\mathrm{pH}$, heavy metal availability and growth of Chenopodium album L. in a soil contaminated by pyritic mine waste, Chemosphere 57, 215-224.

Warren, G.P., Alloway B.J., 2003. Reduction of arsenic uptake by lettuce with ferrous sulfate applied to contaminated soil. Journal of Environmental Quality. 32, 767-772.

Zhang, H., Zhao, F.J., Sun, B., Davison, W., McGrath, S., 2001. A new method to measure effective solution concentration predicts copper availability to plants. Environmental Science \& Technology. 35. pp. 2602-2607.

Zvereva, E. L., Kozlov, M. V., 2007. Facilitation of bilberry by mountain birch in habitat severely disturbed by pollution: Importance of sheltering. Environmental and Experimental Botany. 60,170-176.

Zvereva, E. L., M. V. Kozlov., 2004. Facilitative effects of top-canopy plants on four dwarf shrub species in habitats severely disturbed by pollution. Journal of Ecology 92:288-296. 
The figures

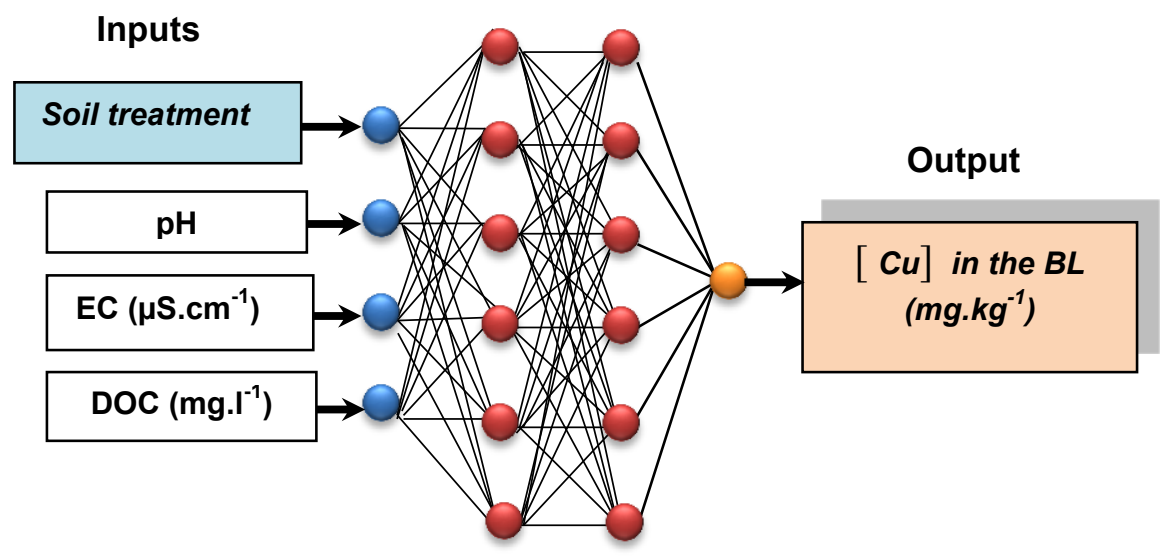

Figure 1. Direct neural network architecture for standard forward modeling composed of 4 inputs, two hidden layers and one output layer. 


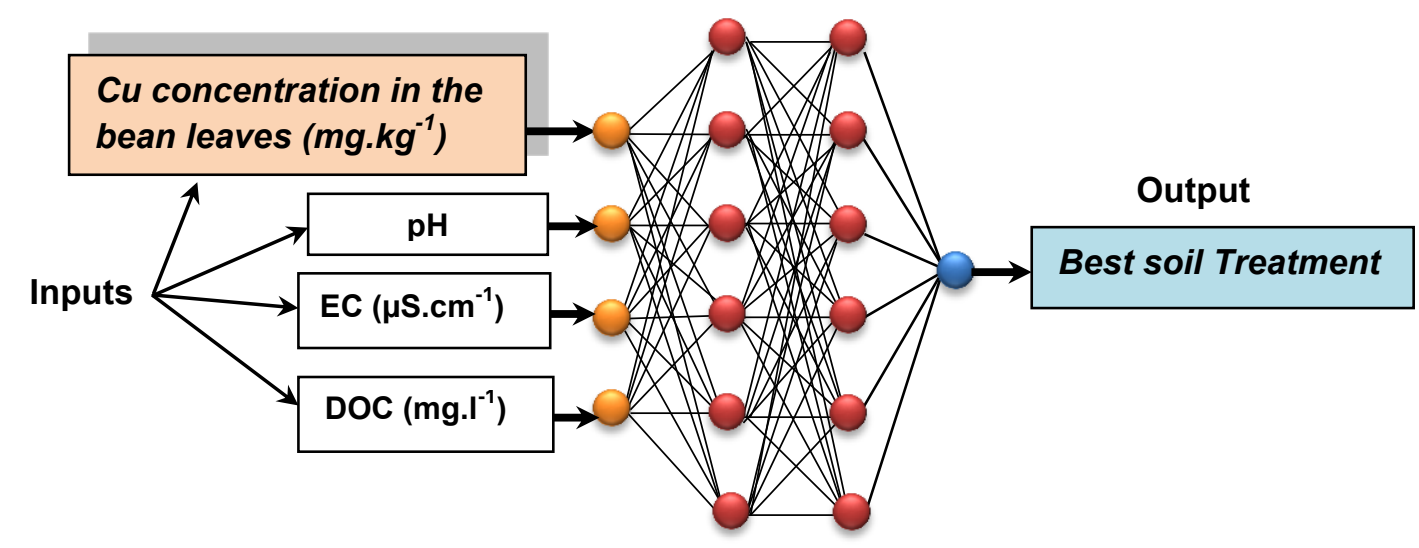

Figure 2. Inverse ANN model for backward modeling composed of 4 inputs, two hidden layers and one output layer. 


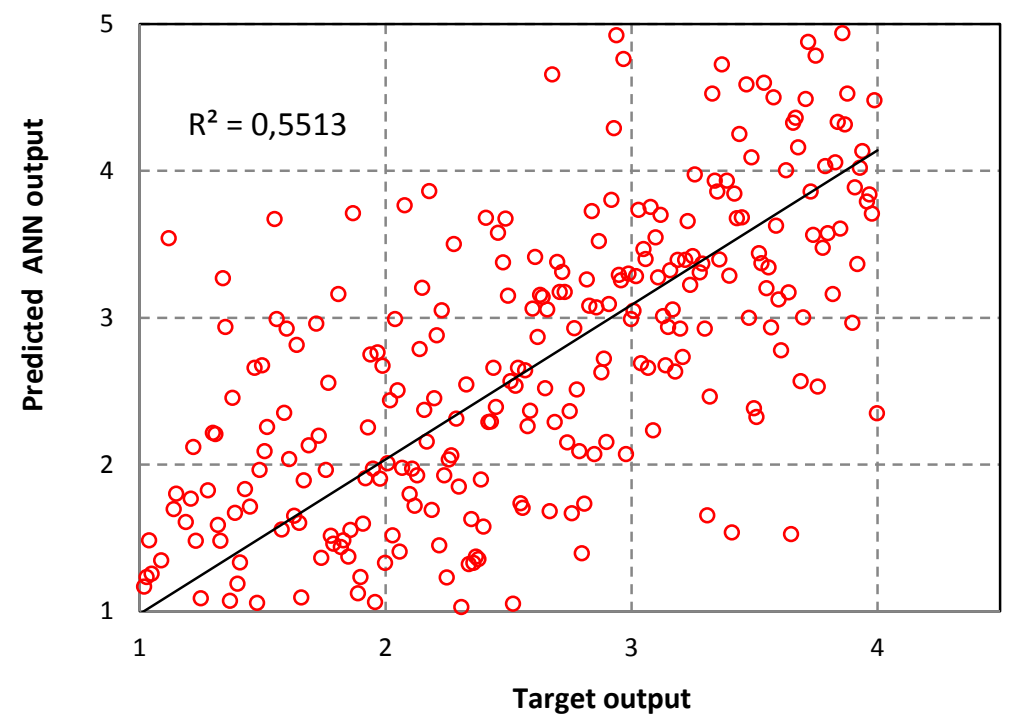

Figure 3. Inverse ANN prediction versus actual soil inputs obtained by an Inverse ANN trained using noise-free training data. Results were obtained for 300 testing combinations of soil inputs.

Outputs 1, 2, 3 and 4 refer to UNT, CPM, DL and DLX CPM soil amendments respectively. 

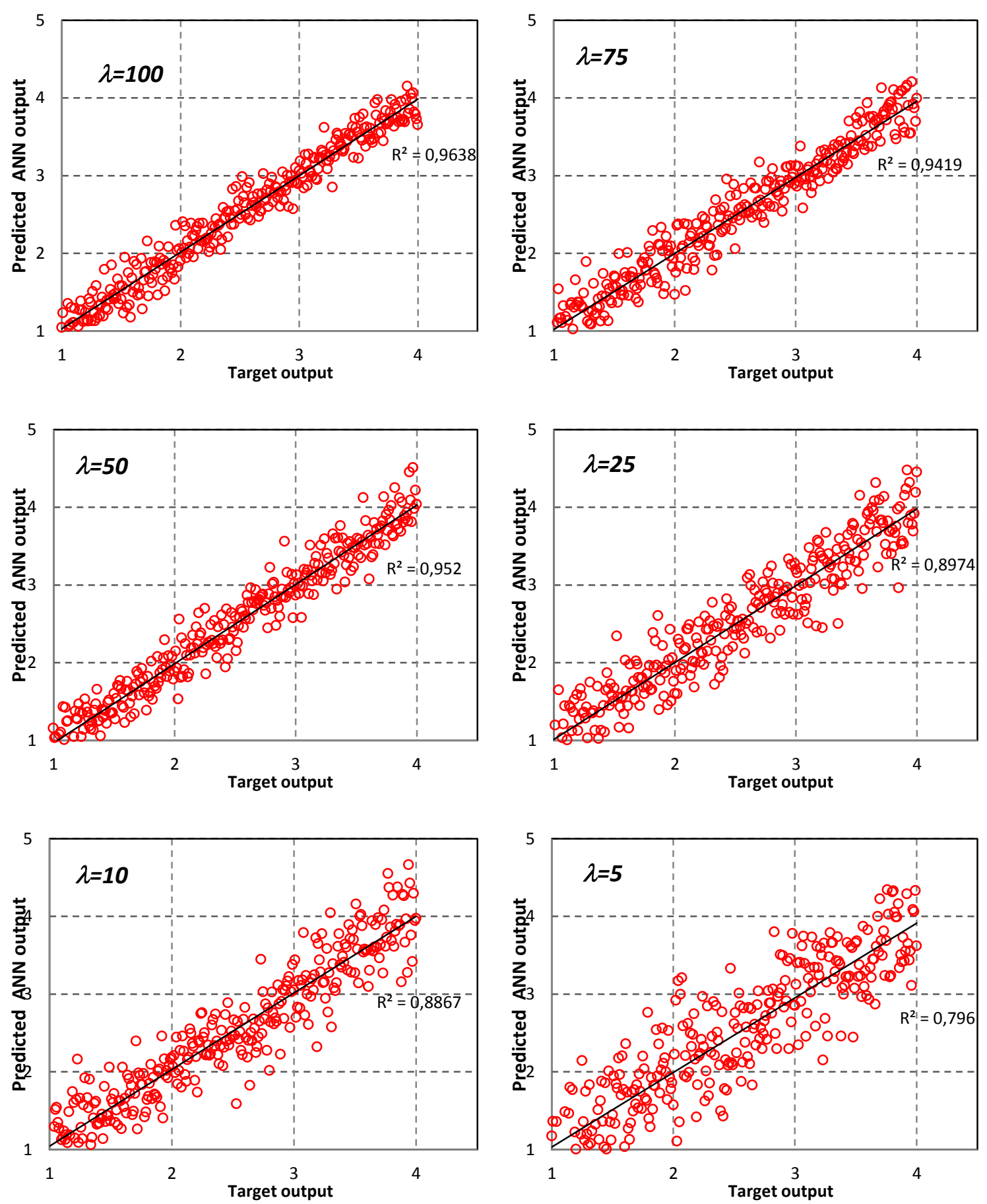

Figure 4. Inverse NN prediction versus actual soil inputs obtained by an ANN trained using noisy training data with decreasing levels of noise. Results were obtained for 300 testing combinations of soil inputs. Outputs 1, 2, 3 and 4 refer to UNT, CPM, DL and DLX CPM soil amendments respectively. 

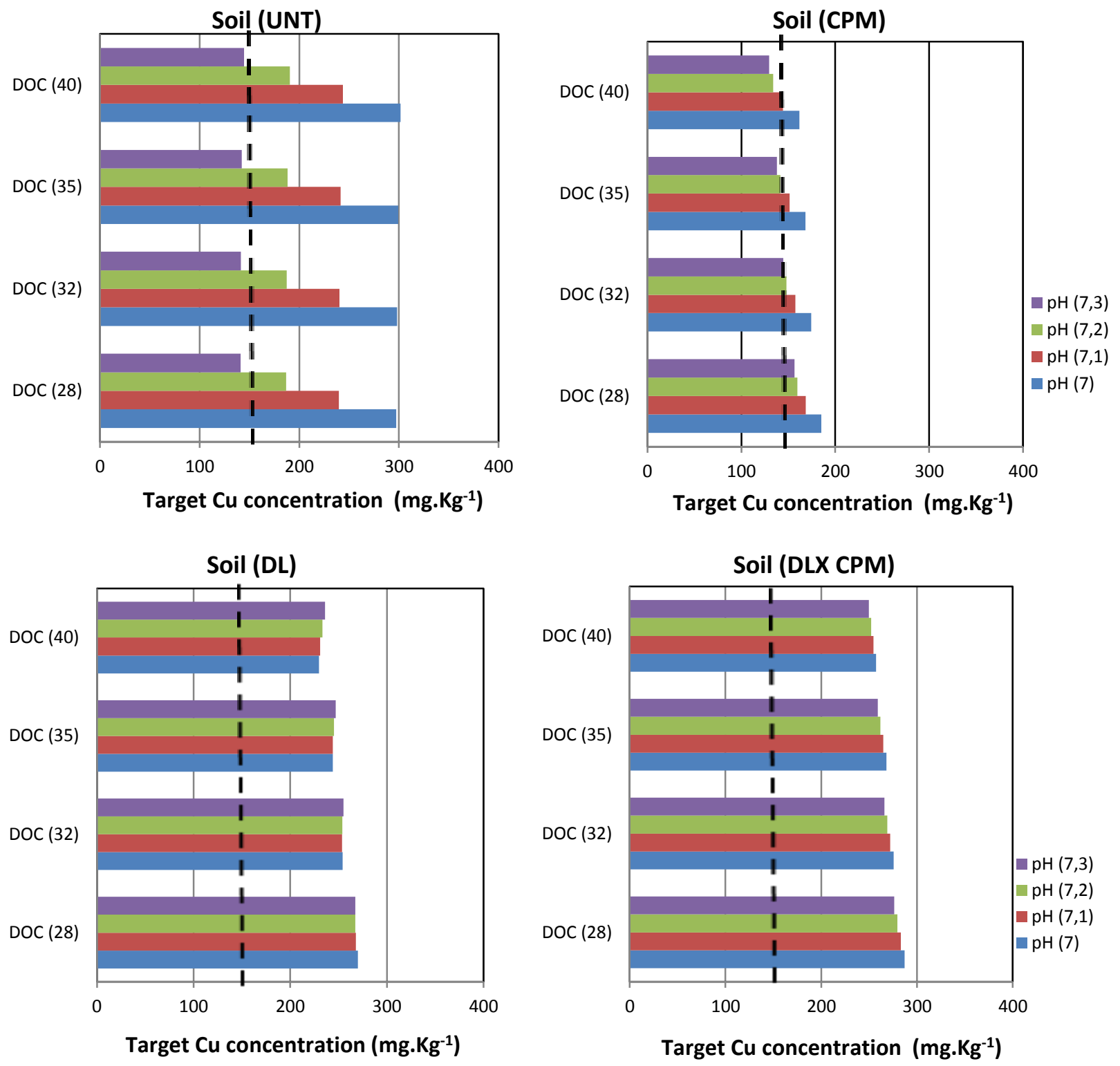

Figure 5. Predicted optimal treatment for soil corresponding to a target value of $\mathrm{Cu}$ concentration in BL of $150 \mathrm{mg} \cdot \mathrm{kg}^{-1}$. Non-uniqueness of the solution related to the effects of soil $\mathrm{pH}$ and DOC can be observed corresponding to the target $\mathrm{Cu}$ concentration indicated by the vertical dashed line $(\lambda=50)$. For illustration, the EC was fixed at $\mu \mathrm{S} . \mathrm{cm}^{-1}$. 


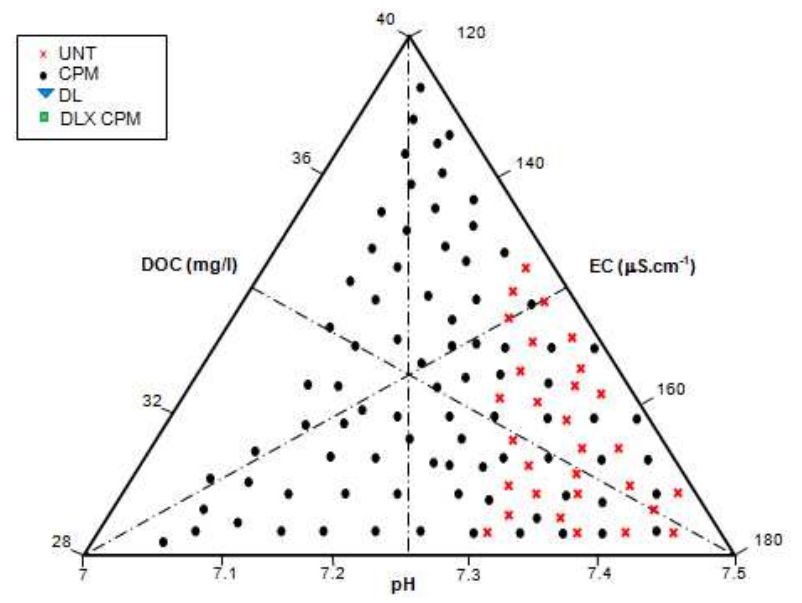

(a) Target $\mathrm{Cu}=150 \mathrm{mg} \cdot \mathrm{kg}^{-1}$

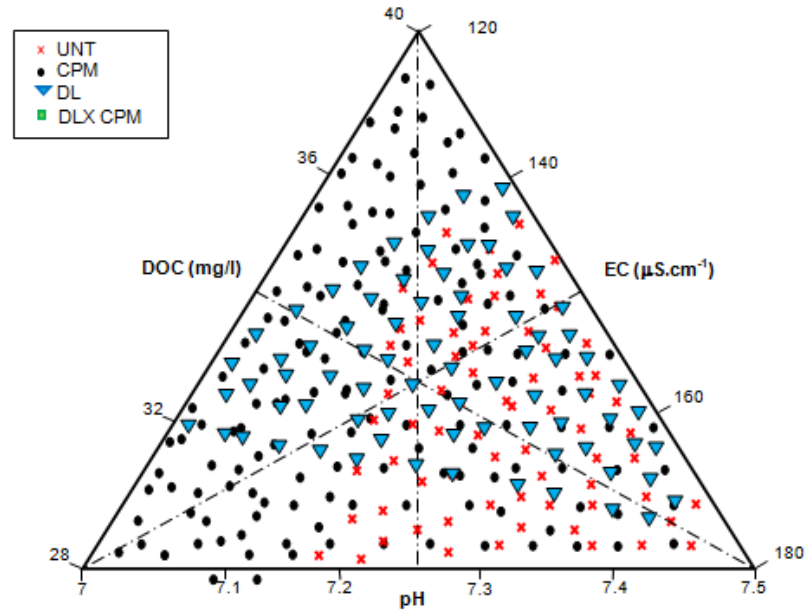

(c) Target $\mathrm{Cu}=250 \mathrm{mg} \cdot \mathrm{kg}^{-1}$

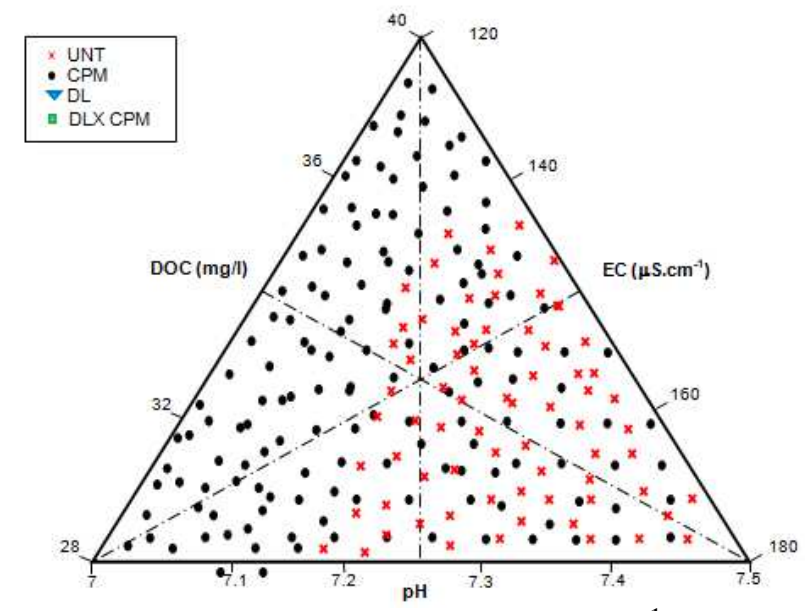

(b) Target $\mathrm{Cu}=200 \mathrm{mg} \cdot \mathrm{kg}^{-1}$

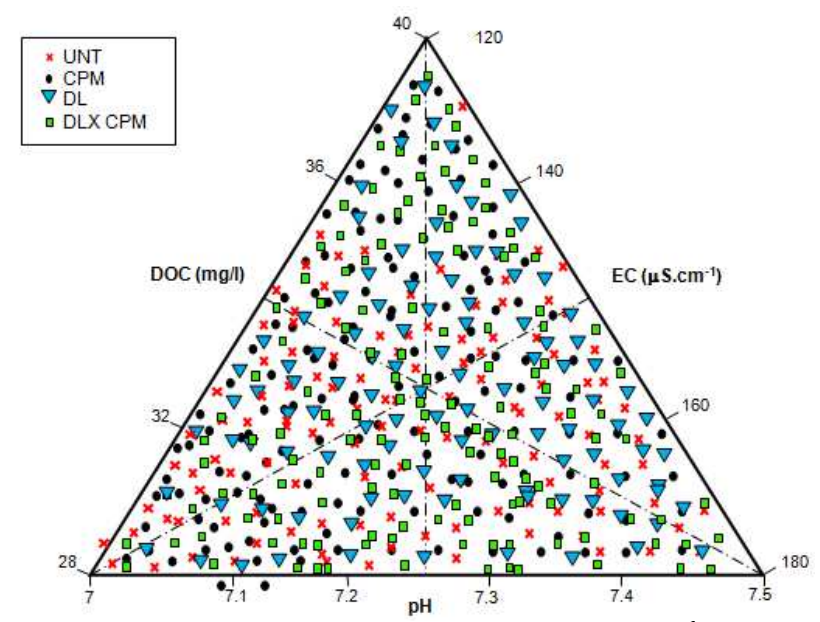

(d) Target $\mathrm{Cu}=300 \mathrm{mg} \cdot \mathrm{kg}^{-1}$

Figure 6. Ternary diagram to classify the predicted optimal treatments for soil corresponding to different target values of $\mathrm{Cu}$ concentration in BL: Effects of soil $\mathrm{pH}, \mathrm{EC}$ and DOC interactions. 


\section{The tables}

\begin{tabular}{|c|c|c|c|}
\hline Inputs & Level & Min value & Max value \\
\hline Soil treatment & 4 & $\# 1$ & $\# 4$ \\
\hline $\mathbf{p H}$ & 4 & 6.97 & 7.55 \\
\hline EC $\left(\boldsymbol{\mu S . c m}{ }^{-1}\right)$ & 4 & 111 & 208 \\
\hline DOC $\left(\mathbf{m g . l}^{-1}\right)$ & 4 & 26.75 & 42.724 \\
\hline \multicolumn{4}{|c|}{ Output } \\
\hline \multicolumn{4}{|c|}{$C u$ concentration in the bean leaves $\left(\mathrm{mg.kg}^{-1}\right)$} \\
\hline
\end{tabular}

Table 1. Selected inputs and output for ANN training. 


\begin{tabular}{|c|c|c|c|c|c|c|}
\hline Inputs & min & max & Level 1 & $\begin{array}{c}\text { Level } \\
\mathbf{2}\end{array}$ & Level 3 & Level 4 \\
\hline $\begin{array}{c}\text { Target Cu } \\
\text { concentration }\left(\mathbf{m g . k g} \mathbf{~}^{-1}\right)\end{array}$ & 10 & 500 & 100 & 200 & 300 & 400 \\
\hline $\mathbf{p H}$ & 6.97 & 7.55 & 7.0 & 7.1 & 7.2 & 7.3 \\
\hline EC $\left(\boldsymbol{\mu S . \mathbf { c m } ^ { - 1 }}\right)$ & 111 & 208 & 120 & 140 & 160 & 180 \\
\hline DOC $\left(\mathbf{m g . l}^{-1}\right)$ & 26.75 & 42.724 & 28 & 32 & 35 & 40 \\
\hline
\end{tabular}

Table 2. Selected four inputs for the inverse ANN prediction. Full factorial combinations generate 256 $(4 \times 4 \times 4 \times 4)$ data set. 